ВІСНИК

ОДЕСЬКОГО НАЦІОНАЛЬНОГО

МОРСЬКОГО УНІВЕРСИТЕТУ
HERALD

OF THE ODESSA NATIONAL

MARITIME UNIVERSITY

№ 1 (61), 2020

УДК 621.629

DOI 10.33082/2226-1893-2019-3-106-120

\title{
КОМПЛЕКСНАЯ ОЦЕНКА \\ РЕЖИМОВ ЭКСПЛУАТАЦИИ СИСТЕМЫ РЕЦИРКУЛЯЦИИ ВЫПУСКНЫХ ГАЗОВ СУДОВЫХ ДИЗЕЛЕЙ
}

\begin{abstract}
А.А. Куропятник
аспирант

Нациинальный университет «Одесская морская академия», Одесса, Украина

Аннотация. Выполнен анализ требований Приложения IV МАРПОЛ относительно эмиссии оксидов азота с выпускными газами судовых дизелей. Рассмотрена система рециркуляичи выпускных газов судового дизеля 7S60MC фирмы Kawasaki MAN-B\&W. B диапазоне степени рециркуляции выпускных газов 0-21\% исследовано изменение концентрации оксидов азота в выпускных газах, а также мощности, удельного эфрективного расхода топлива и температуры выпускных газов. Разработана диаграмма, позволяющая оченить комплексное влияние системы рецииркуляци выпускных газов на экологические, экономические и энергетические показатели работы судового дизеля, а также на его тепловую напряженность.
\end{abstract}

Ключевые слова: Приложение IV МАРПОЛ, судовой дизель, рециикуляция выпускных газов, эмиссия оксидов азота, удельный эффективный расход топлива, эффективная мощность, температура выпускных газов.

УДК 621.629

DOI 10.33082/2226-1893-2019-3-106-120

\section{КОМПЛЕКСНА ОЦІНКА \\ РЕЖИМІВ ЕКСПЛУАТАЦІЇ СИСТЕМИ РЕЦИРКУЛЯЦІЇ ВИПУСКНИХ ГАЗІВ СУДНОВИХ ДИЗЕЛІВ}

\author{
О.А. Куропятнік \\ аспірант \\ Національний університет «Одеська морська академія», Одеса, Украӥна
}

Анотація. Виконано аналіз вимог Додатка IV МАРПОЛ щуодо емісї оксидів азоту з випускними газами суднових дизелів. Розглянуто систему рециркуляиії випускних газів суднового дизеля 7S60MC фірми Kawasaki MAN$B \& W$. B діапазоні ступеня рециркуляиії випускних газів 0-21\% досліджено зміну кон-центрації оксидів азоту в випускних газах, а також потужності, питомої ефективної витрати палива та температури випускних газів. Розроблено діаграма, щзо дозволяє оичінити комплексний вплив системи рециркуляиії випускних газів на екологічні, економічні $i$ енергетичні показники роботи суднового дизеля, а також на його теплову напруженість.

(C) Куропятник А.А., 2020 
ВІСНИК

ОДЕСЬКОГО НАЦІОНАЛЬНОГО

МОРСЬКОГО УНІВЕРСИТЕТУ

№ 1 (61), 2020
HERALD

OF THE ODESSA NATIONAL

MARITIME UNIVERSITY

Ключові слова: Додаток IV МАРПОЛ, судновий дизель, рецчиркулячія випускних газів, емісія оксидів азоту, питома ефективна витрата палива, ефективна потужність, температура випускних газів.

UDK 621.629

DOI 10.33082/2226-1893-2019-3-106-120

\section{COMPREHENSIVE ASSESSMENT OF OPERATING MODES OF THE EXHAUST GAS RECIRCULATION SYSTEM FOR MARINE DIESEL ENGINES}

\section{O. Kuropyatnyk \\ graduate student}

National University «Odessa Maritime Academy», Odessa, Ukraine

Abstract. The analysis of the requirements of MARPOL Annex IV regar-ding the emission of nitrogen oxides with exhaust gases of marine diesel engines is carried out. The range of possible values of the concentration of nitrogen oxides in the exhaust gases of marine diesel engines is indicated, depending on the year of their construction. The mechanism of the formation of nitrogen oxides during fuel combustion is described. The review of primary (Exhaust Gas Recirculation systems, humidification of boost air, the use of water-fuel emulsions, the use of direct injection of water into the diesel cylinder, modernization of the design of fuel equipment) and secondary (selective and non-selective reduction of nitrogen oxides to elementary nitrogen) methods for reducing the emission of nitrogen oxides in the exhaust gases.

The exhaust gas recirculation system for marine diesel engine 7S60MC by Kawasaki MAN-B\&W is considered. The scheme of its configuration with basic equipment, as well as the mechanism for ensuring the required degree of exhaust gas recirculation, is outlined.

For loads of marine diesel engine 7S60MC by Kawasaki MAN-B\&W 25,8, 50,7, $75,6,100,7 \%$ in the range of exhaust gas recirculation $0-21 \%$, the change in the concentration of nitrogen oxides in exhaust gases, as well as power, specific effective fuel consumption and temperature of exhaust gases was studied.

It has been established that the use of an exhaust gas recirculation system helps to reduce nitrogen oxide emissions to $35,95 \%$; and also leads to an increase in specific effective fuel consumption (by 3,37\%), a decrease in effective power (by 2,7 $\%)$, and an increase in the temperature of exhaust gases.

A diagram has been developed to evaluate the complex effect of the exhaust gas recirculation system on the environmental, economic, and energy performance of a marine diesel engine, as well as its thermal stress. It was established that the selection of the operating mode of the exhaust gas recirculation system (as a way of ensuring the requirements of the MARPOL Annex VI) should be based on a comprehensive assessment of the following diesel engine performance indicators: nitrogen oxide emissions, specific effective fuel consumption, effective diesel power, exhaust gas temperature, as well as the area of operation of the marine vessel and the operation of the marine power plant.

Keywords: MARPOL Annex IV, marine diesel, exhaust gas recirculation, nitrogen oxide emissions, specific fuel oil consumption, effective power, exhaust gas temperature. 
Постановка проблемы. Получение эффективной мощности в двигателях внутреннего сгорания невозможно без использования топлива (жидкого или газообразного), которое выполняет роль источника энергии. Внедрение на морских и речных судах экологически чистых источников энергии (ветроэнергетика, солнечные батареи) на сегодняшний день не получило широкого распространения и в большей степени основывается на моделировании происходящих процессов. При этом в полной мере не могут быть учтены такие важные факторы, как автономность и длительность морских (а особенно океанских) переходов, а также динамика изменения погодных условий. Таким образом, в ближайшее время главным источником энергии для тепловых двигателей останется углеводородное органическое топливо, при сжигании которого образуются оксиды азота $\mathrm{NO}_{\mathrm{x}}$ (оксид $\mathrm{N}_{2} \mathrm{O}$, монооксид $\mathrm{NO}$ и диоксид $\mathrm{NO}_{2}$ ) [1].

Анализ последних исследований и публикаций. Оксид азота (I) $\mathrm{N}_{2} \mathrm{O}$, образующийся главным образом естественным путем, является несолеобразующим веществом, при сгорании топлива образуется в концентрации, безвредной для человека. Основное отрицательное влияние соединение $\mathrm{N}_{2} \mathrm{O}$ оказывает на увеличение парникового эффекта. Монооксид азота (II) NO представляет собой бесцветный газ, способный вступать в реакцию с рядом солей, галогенами, а также с кислородом с дальнейшим образованием диоксида $\mathrm{NO}_{2}$. Диоксид азота (IV) $\mathrm{NO}_{2}$, является бурым ядовитым газом, превышающим по массе воздух и способным при соединении с водой образовывать азотистую $\mathrm{HNO}_{2}$ и азотную кислоты $\mathrm{HNO}_{3}$ [2]. Среди комплекса оксидов $\mathrm{NO}_{\mathbf{x}}$ именно $\mathrm{NO}$ являются теми веществами, которые преобладают внутри цилиндра дизеля ( $\approx 0-95 \%)$, в то время как большое количество $\mathrm{NO}_{2}$ образуется только при контакте с низкими температурами, т.е. при попадании выпускных газов в атмосферу. Образование $\mathrm{NO}_{2}$ происходит при соединении $\mathrm{NO}$ с озоном, находящимся в воздухе. В результате чего монооксид $\mathrm{NO}$ преобразуется в диоксид $\mathrm{NO}_{2}$ и кислород $\mathrm{O}_{2}$

$$
\mathrm{NO}+\mathrm{O}_{3} \rightarrow \mathrm{NO}_{2}+\mathrm{O}_{2} .
$$

После чего $\mathrm{NO}_{2}$ соединятся с водяными парами $\mathrm{H}_{2} \mathrm{O}$, что приводит к образованию азотистой кислоты $\mathrm{HNO}_{2}$ и далее азотной кислоты $\mathrm{HNO}_{3}$

$$
\mathrm{NO}_{2}+\mathrm{H}_{2} \mathrm{O} \rightarrow \mathrm{HNO}_{2} \rightarrow \mathrm{HNO}_{2}+\mathrm{O}_{2} \rightarrow \mathrm{HNO}_{3} .
$$

Именно азотная кислота, которая впоследствии конденсируется в воздухе и возвращается на поверхность мирового океана или островную и материковую часть Земли в виде кислотных дождей, является тем соединением, которое наносит экологический ущерб окружающей среде и на борьбу с которым направлены все конструктивные и технологические решения по снижению содержания оксидов азота в выпускных газах (рис. 1). 


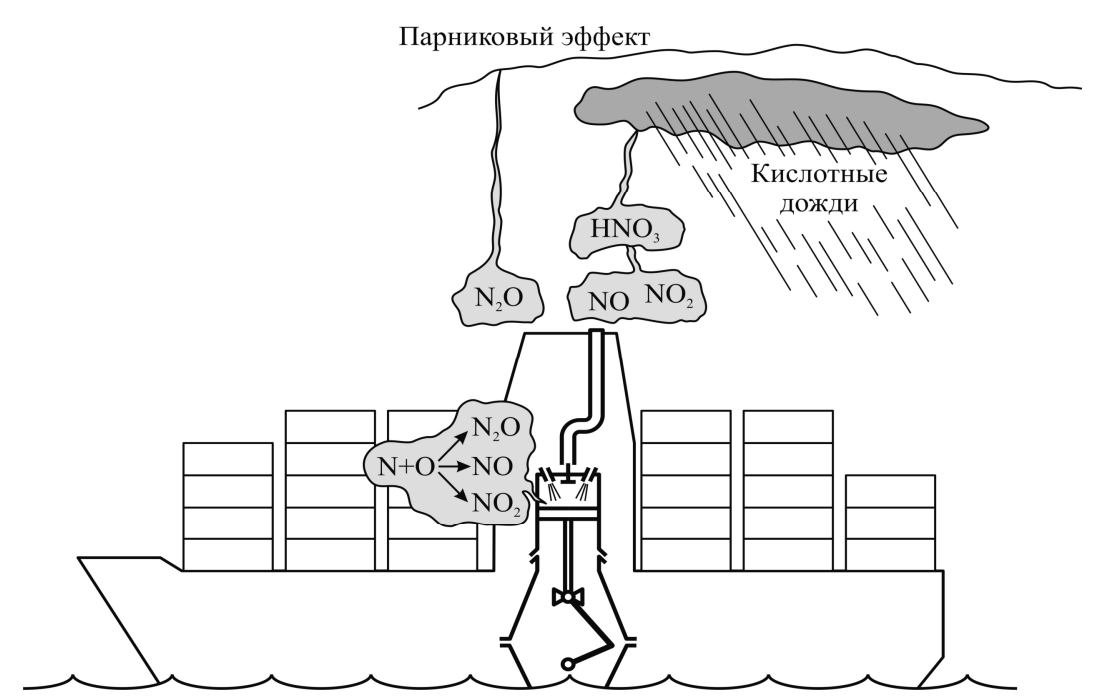

Рис. 1. Механизм образования оксидов азота в судовом дизеле и их влияние на окружаюшую среду

Источниками оксидов азота являются молекулярный азот воздуха, использующийся в качестве окислителя при сгорании топлива, и азотсодержащие компоненты органической массы самого топлива. В соответствии с этим, оксиды азота делятся на воздушные и топливные. Из азота, находящегося в воздухе, образуются термические $\mathrm{NO}_{\mathbf{x}}$ (механизм Зельдовича) и быстрые $\mathrm{NO}_{\mathrm{x}}$ (механизм Фенимора). Из связанного с органической массой азота топлива образуются топливные $\mathrm{NO}_{\mathrm{X}}$ (рис. 2) [3].

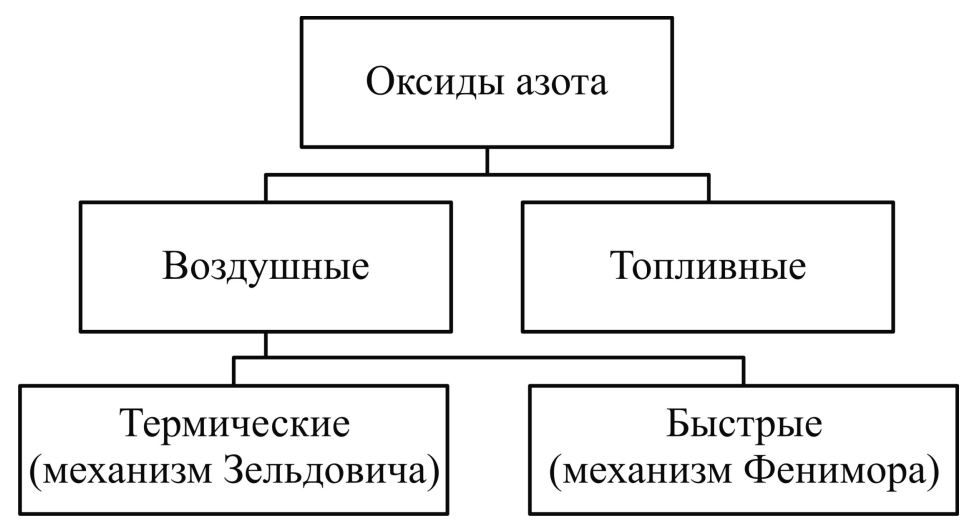

Рис. 2. Классификаџия оксидов азота 
Образование термических $\mathrm{NO}_{\mathrm{X}}$ происходит при максимальной температуре, т.е. в той зоне топливного факела, где уже сгорела основная масса топлива. Быстрые оксиды азота образуются во фронте пламени и зависят главным образом от стехиометрического соотношения в месте их образования. Топливные оксиды азота не образуются при сжигании природного газа (так как он, за редким исключением, не содержит связанного азота). Номограмма распределения типов $\mathrm{NO}_{\mathrm{x}}$ для разных видов топлива представлена в виде рис. 3 .

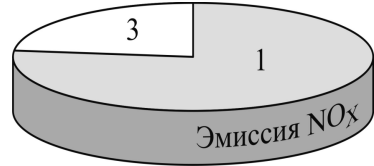

газообразное

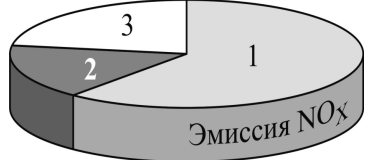

жидкое (легкое)

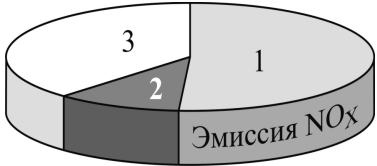

жидкое (тяжелое)

Рис. 3. Номограмма распределения типов $N O_{X}$ для разных видов топлива:

1 - термические (тепловые); 2 -быстрые; 3 - топливные

Нормы выбросов загрязняющих веществ энергетическими установками морских судов (нефтью; вредными жидкими веществами; вредными веществами, перевозимыми в упаковке; сточными водами; мусором; выпускными газами и озоноразрушающими веществами) регламентируются правилами Международной конвенции по предотвращению загрязнения с судов МАРПОЛ (International Convention for the Prevention of Pollution from Ships, MARPOL) [4].

Приложение VI МАРПОЛ (Правила предотвращения загрязнения воздушной среды с судов) устанавливает уровневый подход к сокращению эмиссии оксидов азота с выпускными газами судовых дизелей:

- уровень Tier I представляет собой предел содержания окислов азота $\mathrm{NO}_{\mathrm{X}}$ в выбросах дизелей судов, построенных после 1 января 2000 г., но до 2011 г.;

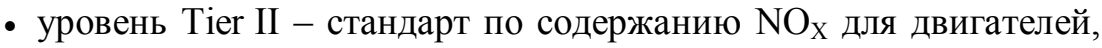
установленных на судах, построенных 1 января 2011 г. или после этой даты;

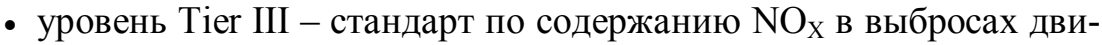
гателей, установленных на судах, построенных 1 января 2016 г. или после этой даты.

В настоящее время на морских транспортных судах используются дизели, соответствующие уровням Tier II и Tier III. При этом выбросы $\mathrm{NO}_{\mathrm{X}}$ двигателей уровня Tier II в зависимости от номинальной частоте вращения коленчатого вала дизеля $n$ в об/мин, должны составлять

- $\quad 14,4$ г/(кВтч) - при $n<130$ об/мин;

- $44 n^{-0,23}-$ при $130<n<2000$ об/мин;

- $\quad 7,7$ г/(кВтч) - при $n \geq 2000$ об/мин. 
Двигатели уровня Tier III должны обеспечивать следующие требования по содержанию $\mathrm{NO}_{\mathrm{x}}$ в выпускных газах:

- $\quad 3,4$ г/(кВтч) - при $n<130$ об/мин;

- $9 n^{-0,2} \Gamma /($ кВТч $)-$ при $130<n<2000$ об/мин;

- 2,0 г/(кВтч) - при $n \geq 2000$ об/мин.

Следует отметить, что выполнение требований уровня Tier II возможно за счет изменения конструкции двигателя. В то же время достижение норм уровня Tier III невозможно без использования специальных технологий, к числу которых могут быть отнесены технологии каталитического восстановления окислов азота до элементарного азота с помощью добавок аммиака или мочевины, а также рециркуляция выпускных газов или переход на сжиженный природный газ.

Системы рециркуляция выпускных газов (Exhaust Gas Recirculation, EGR), как и ряд других методов снижения эмиссии $\mathrm{NO}_{\mathrm{x}}$ (увлажнение воздуха наддува, применение водотопливных эмульсий, использование прямого впрыска воды в цилиндр дизеля, модернизация конструкции топливной аппаратуры) относятся к «первичным» методам и обеспечивают уменьшение непосредственного образования оксидов азота при сгорании топлива. «Вторичные» методы (селективное и неселективное восстановление $\mathrm{NO}_{\mathrm{x}}$ до элементарного азота) подразумевают очистку уже образовавшихся выпускных газов перед их выпуском в атмосферу в дополнительно установленных специальных устройствах (реакторах) [5].

Постановка задачи. Системы EGR в настоящее время используются многими дизелестроительными фирмами для обеспечения требуемых экологических показателей судовых дизелей. При этом до сих пор не существует системного подхода к разработке рекомендаций по их использованию на различных режимах работы двигателей, а также способов определения оптимальных режимов их эксплуатации. Математическое моделирование процессов газообмена и сгорания при использовании системы EGR сопряжено с необходимость учета сложных явлений тепломассопереноса, при этом полученные результаты не учитывают техническое состояние как самого дизеля и его топливной аппаратуры, так и системы EGR. Поэтому совершенствование системы EGR и выбор наиболее оптимальных режимов ее эксплуатации целесообразно осуществлять на базе экспериментальных данных, полученных непосредственно при эксплуатации систем EGR, уже установленных на двигателях внутреннего сгорания морских судов.В связи с этим задачей проведенных исследований было определение оптимальных режимов эксплуатации судовой системы рециркуляции выпускных газов (системы EGR) судового дизеля.

Изложение основного материала исследований. Эксперименты проводились на судовом малооборотном дизеле 7S60MC фирмы Kawasaki MAN-B\&W, работающему по двухтактному циклу и оборудованному штатной системой ERG. Основные характеристики дизеля: диаметр 
цилиндра - 600 мм; ход поршня - 2400 мм; количество цилиндров - 7; номинальная мощность - 13000 кВт; частота вращения, соответствующая номинальной мощности - 102 об/мин. Принципиальная схема системы рециркуляции выпускных газов дизеля 7S60MC Kawasaki MAN-B\&W показана на рис. 4.

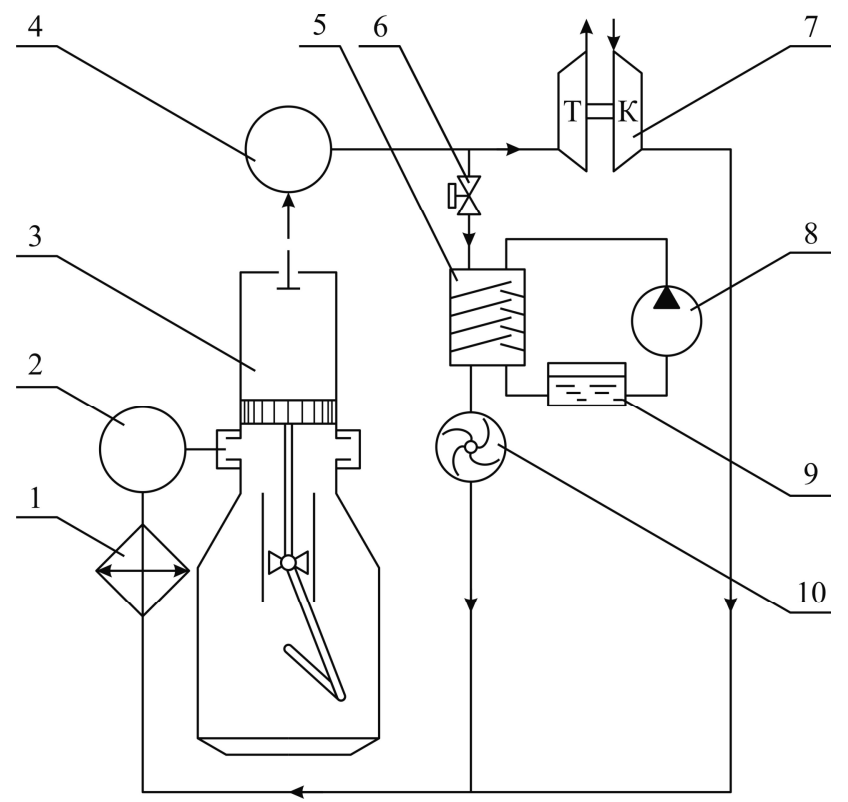

Рис. 4. Принципиальная схема системы рециркуляции выпускных газов судового малооборотного дизеля 7S60MC фирмы Kawasaki MAN-B\&W:

1 - охладитель воздуха; 2 - воздушный ресивер; 3 - ичлиндр дизеля; 4 - выпускной коллектор; 5 - скруббер;

6 - управляюший клапан системы рециируляции выпускных газов; 7 - газотурбонагетатель; 8-водяной насос; 9 - водяная изистерна; 10 - газовый нагнетатель с электрическим приводом

Выпускные газы из цилиндра дизеля 3 поступают в выпускной коллектор 4 и далее к газотурбонагнетателю 7, после чего через газовыпускную трубу удаляются в атмосферу. Газотурбонагнетатель 7 забирает воздух из машинного отделения и после сжатия направляет его через охладитель 1 и ресивер 2 к продувочным окнам дизеля. Система рециркуляции выпускных газов состоит из управляющего клапана 6, скруббера очистки газов 5, нагнетателя 10, водяной цистерны 9 и водяного насоса 8. В случае использования системы рециркуляции выпускных газов их количество регулируется клапаном 6. Выпускные газы очищаются и предварительно охлаждаются в скруббере 5, после чего дополнительным 
нагнетателем подаются на смешение с воздухом (поступающим из газотурбонагнетателя 7) и поступают к охладителю 1 и ресиверу 2 и далее через продувочные окна в цилиндр дизеля 3. В качестве газового нагнетателя 10 используются вентилятор с постоянной геометрией проходного сечения.

Во время проведения экспериментов дизель эксплуатировался на морском тяжелом топливе IFO380 LSFO со следующим структурным составом: содержание углерода - 86,3\%, водорода - $13,17 \%$, серы $0,47 \%$, азота - 0,06 \%. Режимы работа дизеля 7S60MC фирмы Kawasaki MAN-B\&W и основные параметры его работы на этих режимах приведены в таблице 1 .

Таблицуа 1

Основные показатели работы судового дизеля 7S60MC фирмы Kawasaki $M A N-B \& W$ на различных режимах

\begin{tabular}{|l|c|c|c|c|}
\hline \multicolumn{1}{|c|}{ Показатель } & \multicolumn{4}{c|}{ Величина } \\
\hline Нагрузка, \% & 25,8 & 50,7 & 75,6 & 100,7 \\
\hline Мощность, кВт & 3536 & 6940 & 10360 & 13799 \\
\hline Частота вращения, об/мин & 65,5 & 82,7 & 94,6 & 104 \\
\hline $\begin{array}{l}\text { Среднее эффективное давление, } \\
\text { МПа }\end{array}$ & 0,714 & 1,110 & 1,449 & 1,755 \\
\hline $\begin{array}{l}\text { Максимальное давление сгорания, } \\
\text { МПа }\end{array}$ & 6,27 & 9,31 & 12,54 & 13,70 \\
\hline $\begin{array}{l}\text { Удельный эффективный расход } \\
\text { топлива, г/(кВт·ч) }\end{array}$ & 191,2 & 178,4 & 170,2 & 172,0 \\
\hline Температура выпускных газов, ${ }^{\circ} \mathrm{C}$ & 308 & 314 & 322 & 369 \\
\hline
\end{tabular}

Мониторинг эмиссии $\mathrm{NO}_{\mathrm{X}}$ с выпускными газами определялся с помощью газоанализатора Testo350XL производства Германии, позволяющего выполнять измерения в диапазоне температур $-40-1200{ }^{\circ} \mathrm{C}$.

Газоанализатор Testo350XL обеспечивает определение содержания кислорода $\mathrm{O}_{2, \mathrm{Gas}}$, а также оксидов азота $\mathrm{NO}_{\mathrm{X}}$ и азота $\mathrm{N}_{2, \mathrm{Gas}}$ в уходящих газах в диапазоне измерения 0-3000 млн ${ }^{-1}$ с точностью $1 \mathrm{млн}^{-1}$.

Степень рециркуляции уходящих газов во время экспериментов изменялась в диапазон $\mathrm{EGR}=0-21 \%$ и рассчитывалась по выражению

$$
\mathrm{EGR}=\frac{\alpha_{\mathrm{EGR}}}{\alpha} \cdot 100 \%,
$$

где $\alpha$ - текущее значение коэффициента избытка воздуха в зависимости от нагрузки дизеля;

$\alpha_{\mathrm{EGR}}$ - коэффициент избытка воздуха при использовании системы рециркуляции выпускных газов. 
Для определения степени EGR коэффициент избытка воздуха $\alpha$ определялся с учетом объемных концентраций $\mathrm{O}_{2, \text { Gas }}$ и $\mathrm{N}_{2, \text { Gas }}$ в выпускных газах (измеряемых с помощью газоанализатора Testo350XL) по выражению

$$
\alpha=\frac{1}{1-3,76 \frac{\mathrm{O}_{2, \text { Gas }}}{\mathrm{N}_{2, \text { Gas }}}} .
$$

Измерение эмиссии $\mathrm{NO}_{\mathrm{x}}$, а также объемных концентраций $\mathrm{O}_{2, \mathrm{Gas}}$ и $\mathrm{N}_{2, \text { Gas }}$ выполнялось в газовыпускной магистрали на расстоянии $10 \mathrm{M}$ от места выхода газов из газотурбонагнетателя, что соответствовало требованиям Технического кодекса по $\mathrm{NO}_{\mathrm{x}}$.

Результаты определения эмиссии $\mathrm{NO}_{\mathbf{x}}$ с выпускными газами на различных нагрузках дизеля 7S60MC фирмы Kawasaki MAN-B\&W приведены в таблице 2 .

Таблица 2

Эмиссия $N O_{X}, 2 N O_{X} /(\kappa B m \cdot ч)$ судового дизеля 7S60MC

фирмы Kawasaki MAN-B\&W при различных нагрузках и степени EGR

\begin{tabular}{|c|c|c|c|c|c|c|c|c|}
\hline Нагрузка, & \multicolumn{10}{|c|}{ Степень EGR, \% } \\
\cline { 2 - 10 }$\%$ & 0 & 3 & 6 & 9 & 12 & 15 & 18 & 21 \\
\hline 25 & 10,22 & 9,38 & 9,26 & 9,18 & 9,12 & 9,00 & 8,81 & 8,68 \\
\hline 50 & 11,63 & 10,74 & 10,26 & 10,08 & 9,83 & 9,74 & 9,62 & 9,48 \\
\hline 75 & 12,97 & 11,87 & 11,22 & 10,51 & 10,17 & 9,82 & 9,67 & 9,57 \\
\hline 100 & 12,21 & 11,16 & 10,33 & 9,21 & 8,32 & 8,08 & 7,92 & 7,82 \\
\hline
\end{tabular}

Графическая интерпретация результатов измерений показана на рис. 5.

Эффективность использования системы EGR для каждого из режимов работы дизеля возможно определить оценив площадь под кривой $\mathrm{NO}_{\mathrm{X}}=f(\mathrm{EGR})-$ бо́льшие значения площади соответствуют бо́льшей эффективности системы EGR, обеспечивая таким образом меньшее количество образования $\mathrm{NO}_{\mathrm{x}}$ при сгорании топлива. Наиболее целесообразно для этого использовать формулу трапеций $[6 ; 7]$.

Метод применяют для вычисления определенных интегралов непрерывных функций, к которым относится зависимость $\mathrm{NO}_{\mathrm{X}}=f(\mathrm{EGR})$. Интеграл представляют в виде суммы площадей трапеций равной ширины

$$
\int_{a}^{b} f(x) d x \approx \frac{h}{2}\left[f\left(x_{0}\right)+2 f\left(x_{1}\right)+\ldots+2 f\left(x_{n-1}\right)+f\left(x_{n}\right)\right],
$$




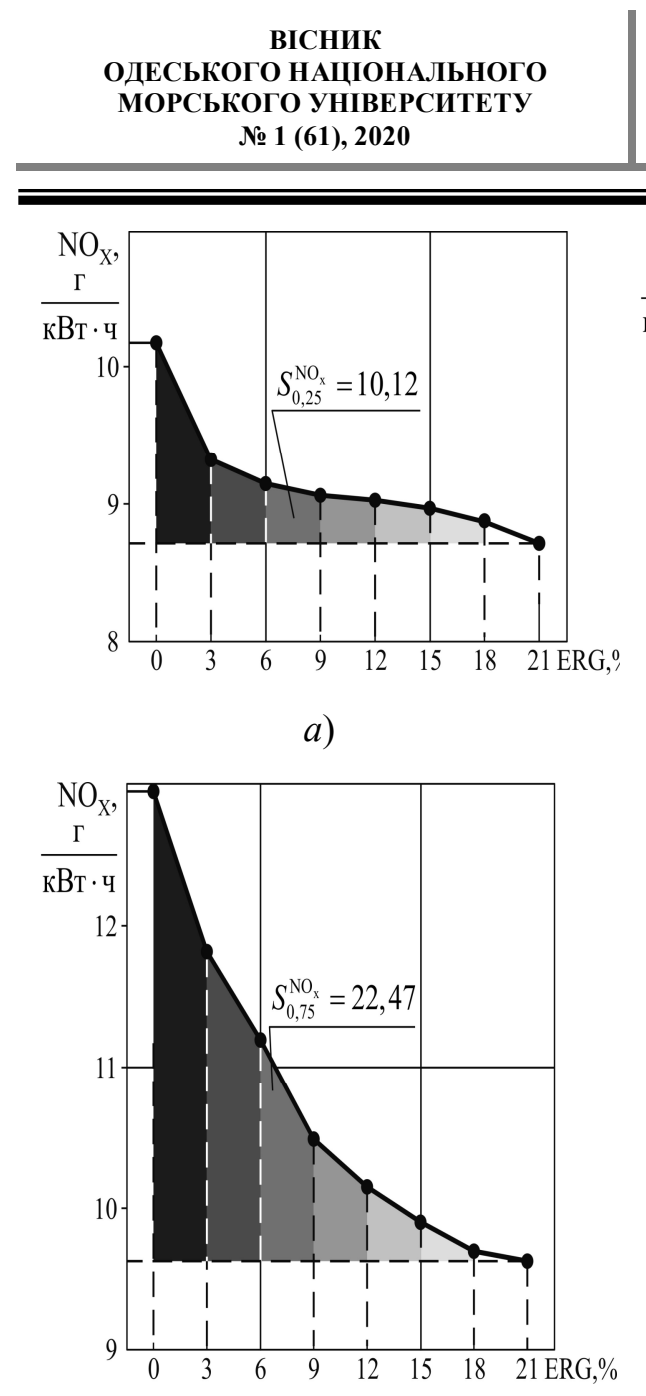

в)
HERALD

OF THE ODESSA NATIONAL

MARITIME UNIVERSITY № 1 (61), 2020

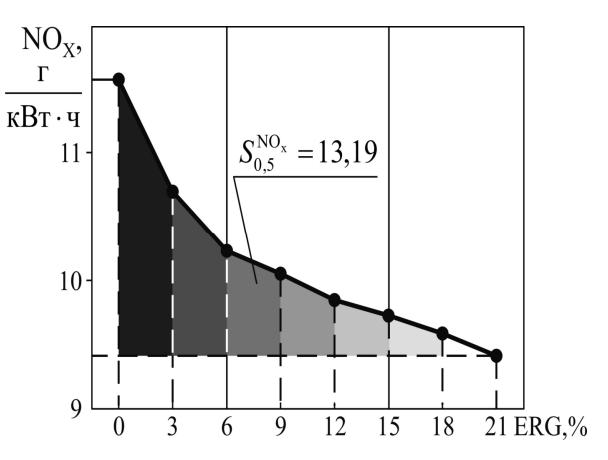

б)

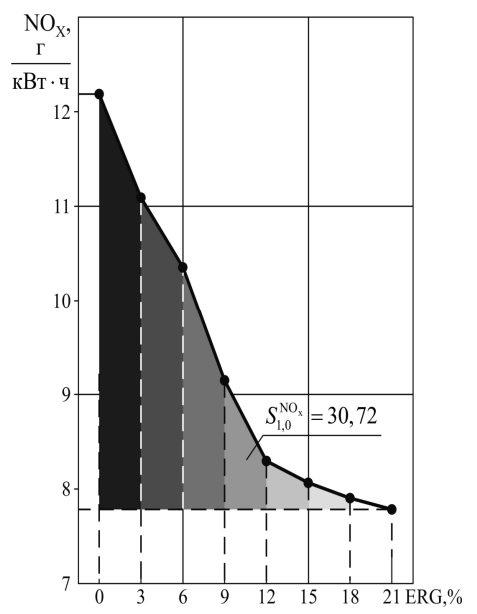

2)

Puc. 5. Изменение эмиссии $N O_{X}$ в зависимости от степени $E G R$ при различных нагрузках дизеля 7S60MC фирмы Kawasaki MAN-B\&W: $a-25 \% ; 6-50 \% ; в-75 \% ; 2-100 \%$

где $f(x)-$ непрерывная функция с аргументом $x$;

$a, b$ - пределы интегрирования $(a \leq x \leq b)$;

$h=(b-f) / n-$ шаг интегрирования;

$x_{0}, x_{1}, \ldots, x_{n-1}, x_{n}$ - значение аргумента с шагом приращения $h$ в интервале интегрирования $[a, b]$;

$n$ - число площадей [8].

Точность формулы тем выше, чем бо́льшим количеством площадей заменяется интеграл. 
Учитывая значения $\mathrm{NO}_{\mathrm{x}}$, приведенные в табл. 1 , получим следующие значения интеграла (1), определяющего площадь под кривой $\mathrm{NO}_{\mathrm{X}}=f(\mathrm{EGR}): S_{0,25 N_{\mathrm{e}}}^{\mathrm{NO}_{\mathrm{x}}}=10,12 ; S_{0,5 N_{\mathrm{e}}}^{\mathrm{NO}_{\mathrm{x}}}=13,19 ; S_{0,75 N_{\mathrm{e}}}^{\mathrm{NO}_{\mathrm{X}}}=22,47 ; S_{1,0}^{\mathrm{NO} \mathrm{X}_{\mathrm{X}}}=30,72$.

Использование системы EGR приводит к изменению не только уровня эмиссии $\mathrm{NO}_{\mathrm{x}}$ с выпускными газами, но также и ряда других показателей работы дизеля. Это связано с тем, что подача в цилиндр дизеля отработавших газов изменяет стехиометрическое соотношение топливовоздух. При этом каждому степени EGR соответствуют разные значения таких показателей, как удельный эффективный расход топлива $b_{\mathrm{e}}$, эффективная мощность $N_{\mathrm{e}}$, температура выпускных газов $t_{\mathrm{r}}$. Их изменение для различной степени EGR при 100 \%-ой нагрузке дизеля 7S60MC фирмы Kawasaki MAN-B\&W приведено в таблице 3.

Таблица 3

Изменение параметров работы судового дизеля 7S60MC фирмы Kawasaki MAN-B\&W при различной степени EGR

\begin{tabular}{|c|c|c|c|c|c|c|c|c|}
\hline \multirow{2}{*}{ Показатель } & \multicolumn{8}{|c|}{ Степень EGR, \% } \\
\cline { 2 - 10 } & 0 & 3 & 6 & 9 & 12 & 15 & 18 & 21 \\
\hline$b_{\mathrm{e}},{ }^{\mathrm{r}} /($ кВт·ч) & 172,0 & 172,6 & 173,0 & 173,8 & 174,6 & 175,5 & 176,7 & 177,8 \\
\hline$N_{\mathrm{e}}$, кВт & 13799 & 13731 & 13703 & 13621 & 13593 & 13552 & 13490 & 13427 \\
\hline$t_{\mathrm{r}},{ }^{\circ} \mathrm{C}$ & 369 & 373 & 376 & 381 & 386 & 390 & 397 & 407 \\
\hline
\end{tabular}

Комплексная номограмма, отражающая изменение указанных показателей, а также уровня эмиссии $\mathrm{NO}_{\mathrm{x}}$ с выпускными газами приведена на рис. 6.

Выводы и перспективы дальнейших исследований. Анализ приведенных результатов позволяет сделать следующие выводы.

1. Отсутствие системного подхода к вопросам определения оптимальных режимов эксплуатации систем рециркуляции выпускных газов судовых дизелей (EGR систем) обязывает выполнять дополнительные исследования, направленные на разработку методики оценки влияния регулируемых параметров системы EGR (степени EGR) на экологические, экономические и эксплуатационные показатели работы судовых дизелей.

2. Использование системы EGR способствует снижению эмиссии оксидов азота с выпускными газами судовых дизелей. Для судового малооборотного дизеля 7S60MC фирмы Kawasaki MAN-B\&W в диапазоне эксплуатационных нагрузок 25-100 \% и степени EGR 0-21 \% сниже-

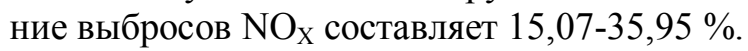


ВІСНИК

ОДЕСЬКОГО НАЦІОНАЛЬНОГО МОРСЬКОГО УНІВЕРСИТЕТУ № 1 (61), 2020
HERALD

OF THE ODESSA NATIONAL MARITIME UNIVERSITY № 1 (61), 2020

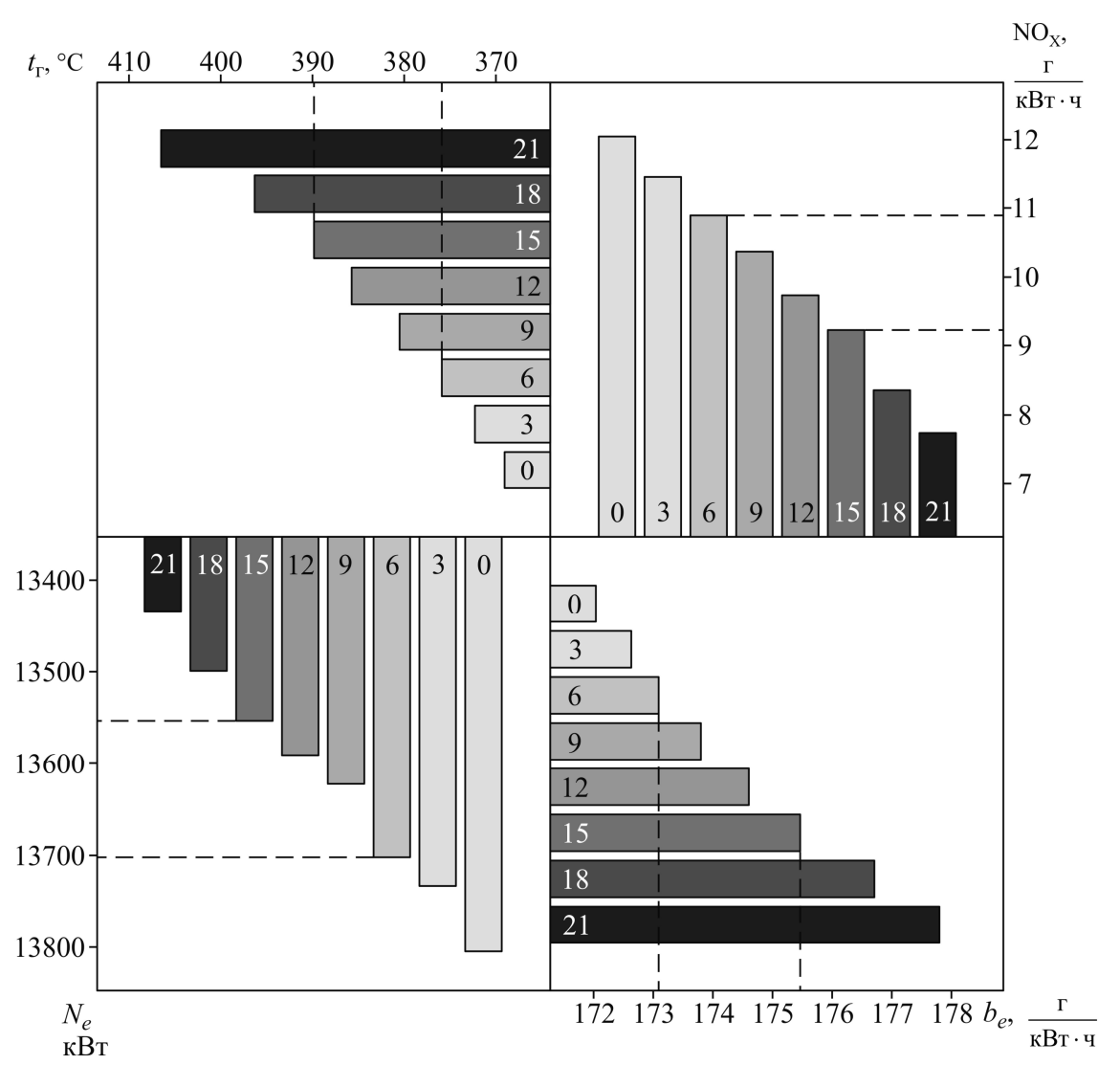

Рис. 6. Изменение эмиссии $N O_{X}$ с выпускными газами, удельного эффективного расхода топлива $b_{e}$, эффективной мощности $N_{e}$, температуры выпускных газов $t_{2}$ при $100 \%$-й нагрузке дизеля 7S60MC фирмы Kawasaki MAN-B\&W для различной степени EGR (0-21\%)

3. Использование системы EGR ухудшает экономические и энергетические показатели работы судового дизеля. При $100 \%$ нагрузке в диапазоне степени EGR 0-21 \% происходит увеличение удельного эффективного расхода топлива (на $3,37 \%$ ) и снижение эффективной мощности (на $2,7 \%$ ). Указанное связано с нарушением стехиометрического соотношения воздух-топливо при использовании системы EGR и снижением максимальной температуры цикла.

4. В случае использования системы EGR происходит увеличение температуры выпускных газов, которое для некоторых значений степени EGR может превышать максимально допустимые значения. Для рассмотренного дизеля 7S60MC фирмы Kawasaki MAN-B\&W максимальное значение температуры выпускных газов ограничивается значением $390^{\circ} \mathrm{C}$, при этом для значений степени EGR $>15 \%$ происходит превышение дан- 
ного параметра, что (из-за изменения уменьшения процентного содержания в цилиндре дизеля воздуха в случае рециркуляции выпускных газов) объясняется смещением процесса сгорания на линию расширения и возможным догоранием топлива в процессе выпуска газов.

5. Выбор режима работы системы EGR (как одного из способов обеспечения требований Приложения VI MAРПОЛ) должен осуществляться на базе комплексной оценки следующих показателей работы дизеля: эмиссии $\mathrm{NO}_{\mathrm{x}}$, удельного эффективного расхода топлива, эффективной мощности дизеля, температуры выпускных газов, а также района работы морского судна и эксплуатации судовой энергетической установки [9].

\section{СПИСОК ЛІТЕРАТУРИ}

1. Куропятнік О.А. Зниження емісії оксидів азоту суднових дизелів методом перепуску випускних газів / О.А. Куропятнік // Вісник Одеськ. нац. мор. ун-ту, 2018. Bun. 4(57). C. 98-108.

2. Sagin S.V. The Use of Exhaust Gas Recirculation for Ensuring the Environmental Performance of Marine Diesel Engines / S.V. Sagin, Kuropyatnyk O.A. // OUR SEA: International Journal of Maritime Science \& Technology. June 2018. Vol. 65. № 2 . P. 78-86. DOI.org/10.17818/NM/ 2018/2.3.

3. Kuropyatnyk O.A. Exhaust Gas Recirculation as a Major Technique Designed to Reduce NOx Emissions from Marine Diesel Engines / O.A. Kuropyatnyk, S.V. Sagin // OUR SEA: International Journal of Maritime Science \& Technology. 2019. Vol. 66. Iss. 1. P. 1-9. DOI.org/10.17818/NM/2019/1.1.

4. Sagin S. V. Application of the system of recirculation of exhaust gases for the reduction of the concentration of nitric oxides in the exhaust gases of the ship diesels / S.V. Sagin, A.A. Kuropyatnik // American Scientific Journal, 2017. № 15. Iss. 2. P. 67-71.

5. Kuropyatnyk O.A. Reduction of $\mathrm{NO}_{x}$ emission in the exhaust gases of low-speed marine diesel engines / O.A. Kuropyatnyk//Austrian Journal of Technical and Natural Sciences, Vienna-2018. № 7-8 (July-August). P. 37-42. DOI.org/10.29013/AJT-18-7.8-37-42.

6. Sagin S.V. Estimation of Operational Properties of Lubricant Coolant Liquids by Optical Methods / S.V. Sagin, V.G. Solodovnikov // International Journal of Applied Engineering Research. 2017. Vol. 12. Num. 19. P. 8380-8391.

7. Куропятник А.А. Управление выпускныли газами судовых дизелей для обеспечения экологических показателей / А.А. Куропятник, С.В. Сагин // Автоматизация судовых технических средств: научн.-техн. сб.2018. Bыл. 24. С. 72-80. 
8. Сагин С.В. Оптимизачия режимов работы системы перепус$к а$ выпускных газов судовых среднеоборотных дизелей / С.В. Сагин, А.А. Куропятник // Автоматизация судовых технических средств: научн. -техн. сб. 2019. Bып. 25. Одесса: НУ «OMA». C. 79-89. DOI: 10.316553/1819-3293-2019-25-79-89.

9. Golikov V.A. A simple technique for identifying vessel model parameters / V.A.Golikov, V.V. Golikov, Ya. Volyanskaya, O. Mazur, O. Onishchenko // IOP Conference Series: Earth and Environmental Science. 4th International Scientific Conference SEA-CONF 2018, Published by IOP Publishing Ltd, 2018. Vol. 172. № 012010. P. 1-8. DOI:10.1088/1755-1315/172/1/012010.

\section{REFERENCES}

1. Kuropyatnyk O. A. (2018) Znyzhennya emisiyi oksydiv azotu sudnovyx dyzeliv metodom perepusku vypusknyx gaziv [Reduction of nitrogen oxides of marine diesel by exhaust gas bypass]. Visnyk Odeskogo nacionalnogo morskogo unyversytetu, no. 4(57), pp. 98-108.

2. Sagin S.V., Kuropyatnyk O.A. (2018) The Use of Exhaust Gas Recirculation for Ensuring the Environmental Performance of Marine Diesel Engines. OUR SEA: International Journal of Maritime Science \& Technology, vol. 65, no 2, pp. 78-86. DOI.org/ 10.17818/NM/2018/2.3.

3. Kuropyatnyk O.A., Sagin S.V. (2019) Exhaust Gas Recirculation as a Major Technique Designed to Reduce NOx Emissions from Marine Diesel Engines. OUR SEA: International Journal of Maritime Science \& Technology, vol. 66, no. 1, pp. 1-9. DOI.org/ 10.17818/ NM/2019/1.1.

4. Sagin S.V., Kuropyatnyk O.A. (2017) Application of the system of recirculation of exhaust gases for the reduction of the concentration of nitric oxides in the exhaust gases of the ship diesels. American Scientific Journal, no. 15, iss. 2, pp. 67-71.

5. Kuropyatnyk O.A. (2018) Reduction of $\mathrm{NO}_{x}$ emission in the exhaust gases of low-speed marine diesel engines. Austrian Journal of Technical and Natural Sciences, no. 7-8, pp. 37-42. DOI.org/ 10.29013/AJT-18-7.8-37-42

6. Sagin S.V., Solodovnikov V.G. (2017) Estimation of Operational Properties of Lubricant Coolant Liquids by Optical Methods. International Journal of Applied Engineering Research, vol. 12, no. 19, pp. 8380-8391. 
ВІСНИК

ОДЕСЬКОГО НАЦІОНАЛЬНОГО

МОРСЬКОГО УНІВЕРСИТЕТУ

№ 1 (61), 2020
HERALD

OF THE ODESSA NATIONAL

MARITIME UNIVERSITY

№ 1 (61), 2020

7. Kuropyatnyk O.A., Sagin S.V. Upravlenie vypusknymi gazami sudovyh dizelej dlya obespecheniya ekologicheskih pokazatelej [Controlling the exhaust gases of marine diesel engines to ensure environmental performance]. Avtomatizaciya sudovyh tehnicheskih sredstv: nauchno-tehnicheskij sbornik, no. 24, pp. 72-80.

8. Sagin S.V., Kuropyatnyk O.A. (2019) Optimizaciya rezhimov raboty sistemy perepuska vypusknyh gazov sudovyh sredneoborotnyh dizelej [Optimization of operating modes exhaust gas wastegate system of marine medium speed diesel]. Avtomatizaciya sudovyh tehnicheskih sredstv: nauchnotehnicheskij sbornik, no. 25, pp. 79-89. DOI: 10.316553/ 18193293-2019-25-79-89.

9. Golikov V.A., Golikov V.V., Volyanskaya Ya., Mazur O., Onishchenko O. (2018) A simple technique for identifying vessel model parameters. IOP Conference Series: Earth and Environmental Science. 4th International Scientific Conference SEA-CONF, vol. 172, no. 012010, pp. 1-8. DOI:10.1088/1755$1315 / 172 / 1 / 012010$

Стаття надійшла до редакиії 10.03.20

Посилання на статтю: Куропятник А.А. Комплексная оценка режимов эксплуатации системы рециркуляции выпускных газов судовых дизелей // Вісник Одеського національного морського університету: Зб. наук. праць, 2020. № 1(61). C. 106-120. DOI 10.47049/2226-1893-2020-1-106-120.

Article received 10.03.20

Reference a JournalArtic: Kuropyatnyk, O. Comprehensive assessment of operating modes of the exhaust gas recirculation system for marine diesel engines. $1(61)$, 106-120. Herald of the Odessa national maritime university. DOI 10.47049/ 2226-1893-2020-1-106-120. 